\title{
Doenças infecciosas em crianças pré-escolares brasileiras assistidas em creches
}

\author{
Infectious diseases among Brazilian preschool children \\ attending daycare centers
}

Dixis Figueroa Pedraza ${ }^{1}$

Daiane de Queiroz ${ }^{2}$

Márcia Cristina Sales ${ }^{1}$
${ }^{1}$ Programa de PósGraduação em Saúde Pública, Universidade Estadual da Paraíba. Av. das Baraúnas 351 Campus Universitário, Bairro Bodocongó. 58.109-753 Campina Grande Paraíba Brasil. dixisfigueroa@gmail.com ${ }^{2}$ Faculdade de Ciências Médicas de Campina Grande.
Abstract The scope of this article is to analyze the prevalence and factors associated with the development of infectious diseases that affect children in daycare centers, namely respiratory infections, diarrheal disease and parasitic infections. Bibliographic research was conducted in the MEDLINE, LILACS and SciELO databases, and observational studies were included. 129 studies were identified, of which 21 were considered relevant to this study, namely two longitudinal and 19 cross-sectional studies. The systematization of the reviewed studies highlighted: i) the presence of intestinal parasites was the main outcome analyzed, followed by respiratory infections; ii) only one study investigated the occurrence of diarrheal disease; iii) the Giardia lamblia was the most prevalent parasitosis; iv) the variables that were most often associated with the development of intestinal parasitosis were child age, family income and maternal education; $v$ ) the attendance at daycare centers was a risk factor for intestinal parasites and respiratory infections. Respiratory and parasitic infections are major problems in institutionalized children in daycare centers. The reduction of such diseases involves a complex web of socio-economic, sanitation and daycare center infrastructure aspects.

Key words Infection, Children, Daycare centers
Resumo O objetivo deste artigo é analisar as prevalências e os fatores associados ao desenvolvimento de doenças infecto-contagiosas que acometem crianças em creches: infecções respiratórias, doença diarreica e infecções por parasitas. Realizou-se uma pesquisa bibliográfica nas bases de dados Medline, Lilacs e SciELO, sendo incluídos estudos observacionais. Foram identificados 129 estudos, dos quais 21 foram considerados relevantes para o presente trabalho: 19 transversais e dois longitudinais. A sistematização dos estudos revisados destaca: i) a presença de enteroparasitoses foi o principal desfecho analisado, seguido das infecções respiratórias; ii) um único estudo investigou a ocorrência de doença diarreica; iii) a Giardia lamblia foi a parasitose mais prevalente; iv) as variáveis que mais vezes mostraram-se associadas ao desenvolvimento de enteroparasitoses foram a idade da criança, a renda familiar e a escolaridade materna; $v$ ) o atendimento em creche foi um fator de risco de enteroparasitoses e de infecções respiratórias. As infecções respiratórias e parasitárias constituem problemáticas importantes nas crianças institucionalizadas em creches cuja redução perpassa uma complexa rede de fatores socioeconômicos, do saneamento básico e da infraestrutura das creches.

Palavras-chave Infecção, Criança, Creches 


\section{Introdução}

A creche vem se tornando uma necessidade da população em consequência das transformações socioeconômicas ocorridas nas últimas décadas, caracterizada por maior inserção da mulher no mercado de trabalho e maior demanda por instituições de assistência integral à criança ${ }^{1}$. Os préescolares constituem uma parcela da população biologicamente vulnerável à aquisição de doenças, devido, sobretudo, a imaturidade do sistema imune e ao rápido crescimento ${ }^{2}$. Estudos demonstram que crianças que frequentam creches adoecem mais que as cuidadas exclusivamente em casa, sendo as doenças infecciosas as mais prevalentes ${ }^{3}$.

Estima-se que $55,3 \%$ das crianças no Brasil apresentam infecção por enteroparasitas. A enteroparasitose na infância assume grande relevância não só pela morbidade, mas também pela associação frequente com diarreia crônica e desnutrição, fatores que podem ocasionar déficit físico e cognitivo, e até mesmo óbito ${ }^{4}$. Alguns estudos têm apresentado dados que evidenciam a importância de enteroparasitoses em ambientes de maior coletividade, principalmente creches ${ }^{5,6}$.

Nos países em desenvolvimento, a maioria dos casos de diarreia aguda e das mortes causadas por diarreia ocorre em crianças menores de cinco anos. A doença é um problema importante nas creches, onde aparece na forma de casos esporádicos ou surtos ${ }^{7}$. Em crianças que frequentam creches a prevalência deste problema é de 60 a $250 \%$ maior ${ }^{8}$.

As doenças respiratórias agudas constituem outro grupo de doenças de importância na população infantil, descritas como a causa mais frequente de mortalidade infantil nos países em desenvolvimento, atingindo principalmente crianças menores de cinco anos de idade ${ }^{9}$. Nessas regiões, estima-se que $25 \%$ a $33 \%$ do total das mortes observadas na população infantil sejam causadas por infecções respiratórias agudas ${ }^{10}$. Para crianças usuárias de creches, cita-se, por exemplo, que a prevalência de pneumonia pode ser de duas a 12 vezes maior e que o risco de adoecer mais por infecção respiratória aguda pode passar de três para cinco quando a permanência em instituições eleva-se de 15 para 50 horas semanais ${ }^{8}$.

O aumento dos casos de doenças em crianças institucionalizadas tem sido associado a fatores como a aglomeração e contato muito próximo com outras pessoas, hábitos que facilitam a disseminação de doenças como levar as mãos e objetos à boca, incontinência fecal e falta de higiene das mãos. Considera-se ainda que, as crianças que frequentam creches, em sua maioria, são de famílias com baixas condições socioeconômicas e com pais de baixo nível educacional, condições estas que podem potencializar os riscos do aparecimento de doenças ${ }^{7}$.

Face ao exposto, o objetivo deste estudo é analisar as prevalências e os fatores associados ao desenvolvimento de doenças infecto-contagiosas que acometem crianças em creches: infecções respiratórias, doença diarreica e infecções por parasitas.

\section{Fonte dos dados}

O estudo é uma revisão sistemática de artigos científicos observacionais sobre a presença de doenças infecciosas em crianças pré-escolares brasileiras assistidas em creches.

Para a identificação dos artigos, realizou-se, em março de 2010, uma busca nas bases de dados Medline (National Library of Medicine, Estados Unidos), Lilacs (Literatura Latino-americana e do Caribe em Ciências da Saúde) e SciELO (Scientific Electronic Library Online) de todos os estudos publicados no período de 1990 a 2009.

A busca bibliográfica foi realizada por dois revisores (DFP e DQ) usando a estratégia de busca: (infecção OR infecções respiratórias OR parasitoses OR diarreia) AND creches, e seus correspondentes em inglês: (infection OR respiratory tract infections OR parasitic diseases OR diarrhea) AND child day care centers. No caso das buscas no Medline, o descritor Brazil também foi usado.

Para o cômputo do total de estudos identificados, foi verificada a duplicação ou triplicação dos mesmos entre as bases de dados, sendo cada artigo contabilizado somente uma vez. A partir dos estudos identificados, foram selecionados aqueles que parecessem preencher os critérios para sua inclusão, considerando a leitura dos títulos e resumos pelos revisores.

Todos os artigos selecionados foram avaliados pelos revisores considerando a leitura e análise criteriosa do texto completo. Após esta ação, os artigos foram classificados como excluídos e incluídos considerando os critérios estabelecidos para esses fins (Quadro 1).

A coleta de dados foi feita sobre os estudos incluídos. As informações selecionadas para a caracterização dos estudos foram: autor e ano de publicação, tipo de estudo, participantes/po- 
Quadro 1. Critérios para a inclusão e exclusão dos artigos na revisão sistemática sobre a presença de doenças infecciosas (infecções respiratórias, doença diarreica, infecções por parasitas) em crianças pré-escolares brasileiras assistidas em creches.

\begin{tabular}{|l|l|l|}
\hline Parâmetros de análise & \multicolumn{1}{|c|}{ Critérios de inclusão } & \multicolumn{1}{c|}{ Critérios de exclusão } \\
\hline Tipos de estudos & - estudos observacionais & $\begin{array}{l}\text { - estudos de intervenção } \\
\text { - artigos de revisão } \\
\text { - livros ou tese }\end{array}$ \\
\hline Participantes & $\begin{array}{l}\text { - crianças brasileiras assistidas em } \\
\text { creches } \\
\text { - amostra representativa e } \\
\text { selecionada aleatoriamente }\end{array}$ & $\begin{array}{l}\text { - estudos realizados fora do Brasil } \\
\text { - crianças não assistidas em creches } \\
\text { - amostra não representativa e/ou } \\
\text { não selecionada aleatoriamente }\end{array}$ \\
& $\begin{array}{l}\text { - infecções respiratórias agudas } \\
\text { - doença diarreica aguda } \\
\text { - infecções por parasitas }\end{array}$ & $\begin{array}{l}\text { - detecção de agentes infecciosos } \\
\text { como objetivo principal } \\
\text { - infecções que acometem múltiplos } \\
\text { órgãos (haemophilusinfluenzae e } \\
\text { citomegalovirose) } \\
\text { - doenças infecciosas da pele (herpes } \\
\text { simples, escabiose, impetigo, } \\
\text { pediculose) } \\
\text { - outras doenças infecciosas } \\
\text { - outros tópicos de estudo (sem } \\
\text { descrição/avaliação de infecções } \\
\text { respiratórias, doença diarreica, } \\
\text { infecções por parasitas) }\end{array}$ \\
\hline
\end{tabular}

pulação, faixa etária, tamanho da amostra e perdas, doenças avaliadas, métodos de diagnóstico das doenças utilizados, variáveis controladas, principais resultados (prevalências e associações estatísticas) e escore de qualidade.

A qualidade dos estudos foi avaliada através de checklist (lista de pontos), preparado pelos pesquisadores. $\mathrm{O}$ checklist consistiu de uma lista adaptada dos critérios de Downs e Black ${ }^{11}$. excluindo os itens relacionados apenas a estudos de intervenção. Para a construção do instrumento, foi considerada a Declaração Strobe ${ }^{12}$ para a comunicação de estudos observacionais e as seguintes diretrizes para a elaboração de listas de avaliação da qualidade de estudos observacionais $^{13}:$ i) o instrumento deve ser de fácil utilização, ter um número pequeno de itens e ser do tipo checklist (evitar a medição em forma de escala); ii) o instrumento não deve deixar de considerar como foi realizada a seleção dos participantes, a medição das variáveis e o controle das variáveis de confusão, assim como o potencial do estudo/desenho para o controle dos vieses associados aos aspectos anteriores.
Sendo assim, analisaram-se os artigos com base na: (1) qualidade da descrição dos objetivos; (2) qualidade da descrição do desfecho de estudo; (3) qualidade da caracterização da amostra (descrição dos participantes e dos critérios de elegibilidade); (4) qualidade da descrição e discussão dos principais fatores de confusão; (5) qualidade da descrição das perdas de participantes; (6) qualidade da descrição dos principais resultados do estudo; (7) comprovação da representatividade da amostra estudada em relação à população de estudo; (8) descrição do cálculo da amostra e do processo de amostragem; (9) acurácia dos instrumentos utilizados para medir o desfecho; (10) apropriação dos testes estatísticos às características das variáveis; (11) avaliação correta dos grupos de comparação (iguais períodos de seguimento para os estudos de coorte, iguais períodos de tempo entre a exposição e o desfecho para os estudos caso controle); (12) adequação dos grupos de comparação (recrutados da mesma população e no mesmo período de tempo); (13) adequação do ajuste para os principais fatores de confusão ou apropriação 
dos testes estatísticos utilizados para seu controle. O escore de qualidade de cada artigo correspondeu à soma do total de itens avaliados como positivos.

\section{Síntese dos resultados}

Inicialmente foram identificados 129 artigos e após análise dos títulos e resumos foram selecionados 72 que aparentemente preenchiam os critérios de inclusão. Com a leitura dos artigos na sua íntegra, foram classificados como incluídos um total de $21^{4,14-33}$ que adequadamente preenchiam todos os critérios de inclusão. O fluxo do número de estudos incluídos encontra-se mostrado na Tabela 1.

Tabela 1. Estudos excluídos e incluídos na revisão sistemática sobre a presença de doenças infecciosas (infecções respiratórias, doença diarreica, infecções por parasitas) em crianças pré-escolares brasileiras assistidas em creches.

\begin{tabular}{|c|c|}
\hline Etapas/critérios de exclusão e inclusão & $\begin{array}{l}\text { No de } \\
\text { artigos }\end{array}$ \\
\hline \multicolumn{2}{|l|}{ Artigos identificados } \\
\hline MEDLINE & 53 \\
\hline LILACS & 93 \\
\hline SCIELO & 20 \\
\hline Estudos em duplicata & 29 \\
\hline Estudos em triplicata & 08 \\
\hline Total de estudos identificados & 129 \\
\hline \multicolumn{2}{|l|}{ Estudos excluídos } \\
\hline - estudos de intervenção* & 02 \\
\hline - artigos de revisão ${ }^{*}$ & 13 \\
\hline - livros ou tese ${ }^{*}$ & 16 \\
\hline - estudos realizados fora do Brasil ${ }^{*}$ & 16 \\
\hline - crianças não assistidas em creches ${ }^{*}$ & 11 \\
\hline $\begin{array}{l}\text { - amostra não representativa e/ou não } \\
\text { selecionada aleatoriamente }^{* *}\end{array}$ & 11 \\
\hline $\begin{array}{l}\text { - detecção de agentes infecciosos } \\
\text { como objetivo principal }^{* *}\end{array}$ & 05 \\
\hline $\begin{array}{l}\text { - infecções que acometem múltiplos } \\
\text { órgãos }\end{array}$ & 04 \\
\hline - doenças infecciosas da pele ${ }^{* *}$ & 02 \\
\hline - outras doenças infecciosas ${ }^{* *}$ & 15 \\
\hline - outros tópicos de estudo ${ }^{* *}$ & 13 \\
\hline Total de estudos excluídos & 108 \\
\hline $\begin{array}{l}\text { Estudos selecionados (leitura de títulos e } \\
\text { resumos) }\end{array}$ & 71 \\
\hline $\begin{array}{l}\text { Estudos incluídos (leitura na íntegra dos } \\
\text { artigos) }\end{array}$ & 21 \\
\hline Total de estudos incluídos & 21 \\
\hline
\end{tabular}

${ }^{*}$ Leitura de títulos e resumos. ${ }^{* *}$ Leitura na íntegra dos artigos.
A Tabela 2 mostra a distribuição dos estudos quanto aos parâmetros de caracterização adotados. Dos 21 artigos incluídos ${ }^{4,14-33}, 19$ apresentam desenho epidemiológico do tipo transversal ${ }^{4,14-17,19-25,27-33}$ e os outros dois são estudos de coorte $^{18,26}$.

A distribuição geográfica dos locais onde foram realizados os estudos mostra maior concentração na região Sudeste $(n=17 \text { estudos })^{4,14-}$ 16,18-20,23-28,30-33. Os demais estudos foram realizados na região Sul $\left(\mathrm{n}=3\right.$ estudos) ${ }^{17,21,29}$ e na região Nordeste $(\mathrm{n}=1 \text { estudo })^{22}$. Considerando o tipo de creche, 13 estudos ocorreram em creches municipais ${ }^{15-17,19-21,23,24,26,28,31-33}$. Em oito estu$\operatorname{dos}^{4,14,18,22,25,27,29,30}$ não foi informado o tipo de instituição e um estudo ${ }^{23}$ envolveu tanto creches municipais como universitárias.

No que concerne ao tamanho amostral dos estudos, observa- se variação de 133 a 500 crianças $(\mathrm{n}=12 \text { estudos })^{4,14-16,18,21,23,24,28-31}$, de 501 a 1000 ( $\mathrm{n}=1$ estudo $)^{22}$ e acima de $1000(\mathrm{n}=8$ estudos) ${ }^{17,19,20,25-27,32,33}$. Os estudos de Chaves et al. ${ }^{17}$, Mascarini e Donalisio ${ }^{19}$ e Mascarini e Donalisio $^{20}$ utilizaram dois cortes em momentos diferentes e o estudo de Barros et al. ${ }^{26}$ analisaram uma amostra de 1110 crianças contando com 443 perdas.

A faixa etária dos estudos apresentou um comportamento heterogêneo. Este fato poderia estar associado à capacidade da creche ou com a disponibilidade da creche de estrutura para berçário. Considerando a idade em anos completos, observa-se que a maioria dos estudos ( $\mathrm{n}=$ 19) considerou crianças de até seis anos de ida$\mathrm{de}^{4,14-17,26-33} \mathrm{e}$ que somente dois estudos não incluíram crianças menores de dois anos ${ }^{15,23}$. Destaca-se, também, que dois estudo ${ }^{24,25}$ compreenderam tanto observações em crianças maiores de seis anos quanto em crianças menores de seis anos.

Em relação às doenças avaliadas, aponta-se que a presença de enteroparasitoses foi o principal desfecho analisado $(\mathrm{n}=17 \text { estudos })^{4,14-}$ 22,24,25,27,28,30,32,33. Enfatiza-se que a ocorrência de enteroparasitose foi estudada de maneira diferente, alguns trabalhos realizaram a especificação do tipo de parasita ${ }^{4,15,16,18,20,21,24,25,27,30}$, outros não realizaram tal especificação ${ }^{14,17,19}$, e outro realizou as análises para grupos de parasitas ${ }^{22}$. A presença de apenas um ou dois parasitas foi avaliada em três trabalhos ${ }^{28,32,33}$. Quatro estudos investigaram a ocorrência de infecções respiratóri$\mathrm{as}^{23,26,29,31}$ e um único estudo investigou a ocorrência de doença diarreica ${ }^{26}$. 
Tabela 2. Características dos artigos sobre a presença de doenças infecciosas (infecções respiratórias, doença diarreica, infecções por parasitas) em crianças pré-escolares brasileiras assistidas em creches.

\begin{tabular}{|c|c|c|c|c|}
\hline Autor, ano & $\begin{array}{l}\text { Tipo de } \\
\text { estudo }\end{array}$ & Participantes/População & Faixa etária & $\begin{array}{c}\text { Tamanho da } \\
\text { amostra (perdas) }\end{array}$ \\
\hline Biscegli et al., $2009^{14}$ & Transversal & Catanduva (SP) & 7-78 meses & $133(3)$ \\
\hline $\begin{array}{l}\text { Barçante et al., } \\
2008^{4}\end{array}$ & Transversal & Vespasiano (MG) & $1-5$ anos & $449(176)$ \\
\hline $\begin{array}{l}\text { Menezes et al., } \\
2008^{15}\end{array}$ & Transversal & $\begin{array}{l}\text { Belo Horizonte (MG) - creches } \\
\text { municipais }\end{array}$ & $3-6$ anos & 472 \\
\hline $\begin{array}{l}\text { Carvalho et al., } \\
2006^{16}\end{array}$ & Transversal & $\begin{array}{l}\text { Botucatu (SP) - creches } \\
\text { municipais }\end{array}$ & $0-6$ anos & 279 \\
\hline Chaves et al., $2006^{17}$ & Transversal & $\begin{array}{l}\text { Uruguaiana (RS) - creches } \\
\text { municipais }\end{array}$ & $\begin{array}{l}5 \text { meses- } \\
6 \text { anos e } 11 \\
\text { meses }\end{array}$ & $\begin{array}{l}\text { Corte 1: } 672 \\
\text { Corte 2: } 616\end{array}$ \\
\hline $\begin{array}{l}\text { Gonçalves et al., } \\
2006^{18}\end{array}$ & $\begin{array}{l}\text { Coorte } \\
\text { retrospectiva }\end{array}$ & São Paulo (SP) & $\begin{array}{l}4 \text { meses- } \\
4 \text { anos }\end{array}$ & 224 \\
\hline $\begin{array}{l}\text { Mascarini; } \\
\text { Donalísio, } 2006^{19}\end{array}$ & Transversal & $\begin{array}{l}\text { Botucatu (SP) - creches } \\
\text { municipais }\end{array}$ & $0-83$ meses & $\begin{array}{l}\text { Corte 1: } 379 \\
\text { Corte 2: } 397\end{array}$ \\
\hline $\begin{array}{l}\text { Mascarini; } \\
\text { Donalísio, } 2006^{20}\end{array}$ & Transversal & $\begin{array}{l}\text { Botucatu (SP) - creches } \\
\text { municipais }\end{array}$ & $0-83$ meses & $\begin{array}{l}\text { Corte 1: } 379 \\
\text { Corte 2: } 397\end{array}$ \\
\hline Pupulin et al., $2004^{21}$ & Transversal & $\begin{array}{l}\text { Maringá (PR) - creches } \\
\text { municipais }\end{array}$ & $0-5$ anos & $\begin{array}{l}\text { Creche 1: } 80(17) \\
\text { Creche 2:29 (11) } \\
\text { Creche 3: } 29(31)\end{array}$ \\
\hline Gurgel et al., $2005^{22}$ & Transversal & $\begin{array}{l}\text { Aracaju (SE) - crianças assistidas } \\
\text { em creches vs. crianças não } \\
\text { assistidas }\end{array}$ & $1-5$ anos & $520(52)$ \\
\hline Veríssimo, $2005^{23}$ & Transversal & $\begin{array}{l}\text { São Paulo (SP) - creches } \\
\text { municipais vs. creches } \\
\text { universitárias }\end{array}$ & 42-69 meses & $\begin{array}{c}\text { Creches } \\
\text { municipais: } 260 \\
\text { (67) } \\
\text { Creches } \\
\text { universitárias: } 229 \\
\text { (126) }\end{array}$ \\
\hline Uchoa et al., $2001^{24}$ & Transversal & Niterói (RJ) - creches municipais & $\begin{array}{l}1-6 \text { anos } \\
7-11 \text { anos }\end{array}$ & $\begin{array}{c}\text { Crianças } \leq 6 \text { anos: } \\
186 \\
\text { Crianças } 7-11 \\
\text { anos: } 28\end{array}$ \\
\hline Rocha et al., $2000^{25}$ & Transversal & $\begin{array}{l}\text { Bambuí (MG) - crianças } \\
\text { assistidas em creches vs. escolares } \\
\text { de } 1^{\circ} \text { e } 2^{\circ} \text { grau }\end{array}$ & $\begin{array}{l}0-6 \text { anos } \\
7-14 \text { anos } \\
>14 \text { anos }\end{array}$ & $\begin{array}{c}\text { Crianças } \leq 6 \text { anos: } \\
255 \\
\text { Crianças } 7-14 \\
\text { anos: } 2190 \\
\text { Crianças > } 14 \\
\text { anos: } 366(90)\end{array}$ \\
\hline Barros et al., $1999^{26}$ & Coorte & $\begin{array}{l}\text { Campinas (SP)- creches } \\
\text { municipais }\end{array}$ & 3-35 meses & $1110(443)$ \\
\hline Coelho et al., $1999^{27}$ & Transversal & Sorocaba (SP) & Pré-escolares & 1050 \\
\hline Franco et al., $1996^{28}$ & Transversal & $\begin{array}{l}\text { Campinas (SP) - creches } \\
\text { municipais }\end{array}$ & 2-60 meses & 310 \\
\hline Fuchs et al., $1996^{29}$ & Transversal & $\begin{array}{l}\text { Porto Alegre (RS) - crianças } \\
\text { assistidas em creche vs. crianças } \\
\text { não assistidas }\end{array}$ & 12-71 meses & 106 \\
\hline $\begin{array}{l}\text { Guimarães e Sogayar, } \\
1995^{30}\end{array}$ & Transversal & Botucatu (SP) & $0-6$ anos & 147 \\
\hline Birar et al., $1994^{31}$ & Transversal & $\begin{array}{l}\text { São Paulo (SP) - crianças } \\
\text { assistidas em creches municipais }\end{array}$ & $\begin{array}{c}3 \text { meses } \\
2 \text { anos e } 11 \\
\text { meses }\end{array}$ & $\begin{array}{c}133 \\
3076\end{array}$ \\
\hline Torres et al., $1992^{32}$ & Transversal & $\begin{array}{l}\text { São Paulo (SP)- creches } \\
\text { municipais }\end{array}$ & $0-6$ anos & \\
\hline Torres et al., $1991^{33}$ & Transversal & $\begin{array}{l}\text { São Paulo (SP) - creches } \\
\text { municipais }\end{array}$ & $0-6$ anos & 3076 \\
\hline
\end{tabular}


Tabela 2. continuação

\begin{tabular}{|c|c|c|}
\hline Autor, ano & Doenças avaliadas & Método de diagnóstico \\
\hline Biscegli et al., $2009^{14}$ & Enteroparasitoses & $\begin{array}{l}\text { - Método Direto } \\
\text { - Sedimentação espontânea } \\
\text { - Baermann-Moraes }\end{array}$ \\
\hline $\begin{array}{l}\text { Barçante et al., } \\
2008^{4}\end{array}$ & Enteroparasitoses & - Método de Blagg \\
\hline $\begin{array}{l}\text { Menezes et al., } \\
2008^{15}\end{array}$ & Enteroparasitoses & - Método de Blagg \\
\hline $\begin{array}{l}\text { Carvalho et al., } \\
2006^{16}\end{array}$ & Enteroparasitoses & $\begin{array}{l}\text { - Método de Ritchie } \\
\text { - Ziehl-Neelsen }\end{array}$ \\
\hline Chaves et al., $2006^{17}$ & Enteroparasitoses & - Sedimentação espontânea \\
\hline Gonçalves et al., & Enteroparasitoses & - Sedimentação espontânea \\
\hline $2006^{18}$ & $\begin{array}{l}\text { (Cryptosporidium } \\
\text { hominis) }\end{array}$ & $\begin{array}{l}\text { - Método de Faust et al. } \\
\text { - Rugai, Matos e Brisola } \\
\text { - Kinyoun }\end{array}$ \\
\hline $\begin{array}{l}\text { Mascarini; } \\
\text { Donalísio, } 2006^{19}\end{array}$ & Enteroparasitoses & $\begin{array}{l}\text { - Método de Faust et al. } \\
\text { - Sedimentação espontânea } \\
\text { - Método de Graham } \\
\text { - Método de Ritchie }\end{array}$ \\
\hline $\begin{array}{l}\text { Mascarini; } \\
\text { Donalísio, } 2006^{20}\end{array}$ & Enteroparasitoses & $\begin{array}{l}\text { - Método de Faust et al. } \\
\text { - Sedimentação espontânea } \\
\text { - Ziehl-Neelsen }\end{array}$ \\
\hline Pupulin et al., $2004^{21}$ & Enteroparsitose & $\begin{array}{l}\text { - Método de Faust et al. } \\
\text { - Sedimentação espontânea }\end{array}$ \\
\hline Gurgel et al., $2005^{22}$ & Enteroparasitoses & - Método de Blagg \\
\hline Veríssimo, $2005^{23}$ & Infecções respiratórias & $\begin{array}{l}\text { - Avaliação de documentos (prontuários, registros de } \\
\text { encaminhamento médico e de problemas de saúde) }\end{array}$ \\
\hline Uchoa et al., $2001^{24}$ & Enteroprasitoses & $\begin{array}{l}\text { - Método de Faust et al. } \\
\text { - Sedimentação espontânea } \\
\text { - Baermann-Moraes }\end{array}$ \\
\hline Rocha et al., $2000^{25}$ & Enteroparasitoses & $\begin{array}{l}\text { - Método Direto } \\
\text { - Kato-Katz }\end{array}$ \\
\hline Barros et al., $1999^{26}$ & $\begin{array}{l}\text { Doença diarreica, } \\
\text { infecções respiratórias }\end{array}$ & $\begin{array}{l}\text { - Fezes líquidas ou semilíquidas (diarreia) } \\
\text { - } \mathrm{T}^{0} \geq 37,5^{\circ} \text {, tosse, retrações subcostais, respiração rápida } \\
\text { (infecção respiratória inferior) } \\
\text { - Tosse, corrimento nasal na ausência de infecção } \\
\text { respiratória inferior (infecção respiratória superior) }\end{array}$ \\
\hline Coelho et al., $1999^{27}$ & $\begin{array}{l}\text { Enteroparasitoses } \\
\quad \text { (Helmintos) }\end{array}$ & - Sedimentação espontânea \\
\hline Franco et al., $1996^{28}$ & $\begin{array}{l}\text { Enteroparasitoses }(G . \\
\text { duodenalis, C. parvum) }\end{array}$ & $\begin{array}{l}\text { - Método de Ritchie } \\
\text { - Concentração por centrífugo-sedimentação em éter-PBS }\end{array}$ \\
\hline Fuchs et al., $1996^{29}$ & Infecções respiratórias & $-\mathrm{T}^{0} \geq 38^{\circ}$, tosse, coriza, estertores, taquipneia, otite \\
\hline $\begin{array}{l}\text { Guimarães e Sogayar, } \\
1995^{30}\end{array}$ & Enteroparasitoses & $\begin{array}{l}\text { - Sedimentação espontânea } \\
\text { - Método de Faust et al. }\end{array}$ \\
\hline Birar et al., $1994^{31}$ & Infecções respiratórias & - Cartão de saúde da criança \\
\hline Torres et al., $1992^{32}$ & $\begin{array}{l}\text { Enteroparasitose ( } E \text {. } \\
\text { histolytica) }\end{array}$ & $\begin{array}{l}\text { - Método Direto } \\
\text { - Sedimentação espontânea }\end{array}$ \\
\hline Torres et al., $1991^{33}$ & $\begin{array}{l}\text { Enteroparasitose }(G . \\
\text { lamblia) }\end{array}$ & - Sedimentação espontânea \\
\hline
\end{tabular}

continua

A coleta de dados envolveu a utilização de exames laboratoriais em 17 estudos ${ }^{4,14-}$ $22,24,25,27,28,30,32,33$ e observações de sinais e sintomas clínicos em dois estudos ${ }^{26,29}$. Veríssimo ${ }^{23} \mathrm{e}$ Bitar et al. $^{31}$, nos seus estudos, realizaram diag- nóstico das doenças de interesse através de fontes secundárias (revisão de documentos). Os exames parasitológicos foram os únicos exames laboratoriais utilizados. Considerando o método adotado para a realização de tais exames, ocor- 
Tabela 2. continuação

\begin{tabular}{|c|c|c|c|}
\hline \multirow[b]{2}{*}{ Autor, ano } & \multicolumn{2}{|c|}{ Principais resultados } & \multirow[b]{2}{*}{ Escore } \\
\hline & Prevalências (\%) & Associações estatísticas & \\
\hline $\begin{array}{l}\text { Biscegli et al., } \\
2009^{14}\end{array}$ & - Enteroparasitoses: 29 & - desnutrição pregressa & 10 \\
\hline $\begin{array}{l}\text { Barçante et al., } \\
2008^{4}\end{array}$ & $\begin{array}{l}\text { - Enteroparasitoses: } 22,7 \\
\text { - Entamoeba coli: } 57,5 \\
\text { - G. duodenalis: } 40 \\
\text { - Entamoeba histolytica: } 15 \\
\text { - Thichuris trichiura: } 7,5 \\
\text { - A. lumbricoides: } 7,5 \\
\text { - Enterobius vermicularis: } 2,5 \\
\text { - Taenia sp.: } 2,5 \\
\text { - Hymenolepis sp.: } 2,5\end{array}$ & $\begin{array}{l}\text { - parasitismos por protozoários foi } \\
\text { maior que por helmintos }\end{array}$ & 10 \\
\hline $\begin{array}{l}\text { Menezes et al., } \\
2008^{15}\end{array}$ & $\begin{array}{l}\text { - Enteroparasitoses: } 24,6 \\
\text { - E. coli: } 14,0 \\
\text { - G. duodenalis: } 9,5 \\
\text { - Endolimax nana: } 3,6 \\
\text { - A. lumbricoides: } 3,0 \\
\text { - T. trichiura: } 1,1 \\
\text { - E. histolytica / E. dispar: } 0,6 \\
\text { - Iodameba butschlli: } 0,4 \\
\text { - Chilomastix mesnili: } 0,4 \\
\text { - Strongyloides stercoralis: } 0,2\end{array}$ & - & 7 \\
\hline $\begin{array}{l}\text { Carvalho et al., } \\
2006^{16}\end{array}$ & $\begin{array}{l}\text { - Enteroparasitoses: } 53,4 \\
\text { - G. duodenalis: } 26,88 \\
\text { - Cryptosporidium sp: } 15,05 \\
\text { - Blastocystis hominis: } 14,34 \\
\text { - E. vermicularis: } 10,04 \\
\text { - E. coli: } 6,81 \\
\text { - A. lumbricoides: } 6,09 \\
\text { - T. trichiria: } 5,73 \\
\text { - E. nana: } 2,15 \\
\text { - H. nana: } 1,08 \\
\text { - S. stercoralis: } 0,72\end{array}$ & $\begin{array}{l}\text { i) Enteroparasitoses: } \\
\text { - renda familiar } \\
\text { - escolaridade da mãe } \\
\text { ii) G. duodenalis: } \\
\text { - idade da criança } \\
\text { iii) E. vermicularis: } \\
\text { - idade da criança } \\
\text { iv) A. lumbricoides, T. trichiria, E. } \\
\text { coli:- idade da criança } \\
\text { v) Cryptosporidium sp, B. hominis, E. } \\
\text { nana, H. nana, S. stercoralis: } \\
\text { - nenhuma associação }\end{array}$ & 10 \\
\hline $\begin{array}{l}\text { Chaves et al., } \\
2006^{17}\end{array}$ & $\begin{array}{l}\text { - Total: } 38,4 \\
\text { - Corte } 1: 41,4 \\
\text { - Corte } 2: 35,2\end{array}$ & 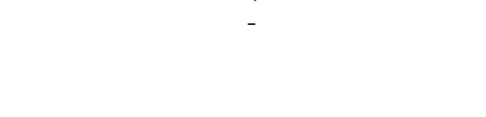 & 7 \\
\hline $\begin{array}{l}\text { Gonçalves et } \\
\text { al., } 2006^{18}\end{array}$ & $\begin{array}{l}\text { - C. hominis: } 12,9 \\
\text { - G.lamblia: } 11,6 \\
\text { - Outros parasitas: } 10,3\end{array}$ & $\begin{array}{l}\text { C. hominis: } \\
\text { - uso de fralda } \\
\text { - uso de água filtrada } \\
\text { - uso de água da torneira } \\
\text { - ingestão de legumes crus }\end{array}$ & 8 \\
\hline
\end{tabular}

reu uma diversidade e superposição em relação às técnicas usadas. A técnica de sedimentação espontânea $^{34}$ foi a de uso mais frequente, uma vez que foi reportada em 11 estudos ${ }^{14,17-21,24,27,30,32,33}$ dos 21 analisados. O método Faust et al. ${ }^{35}$ foi o segundo mais usado. Os pesquisadores que fizeram uso desta última técnica ${ }^{18-21,24,30}$ também consideraram a técnica de sedimentação espontânea ${ }^{34}$ para o diagnóstico das doenças em estudo. Os outros métodos utilizados foram o mé- todo Direto ${ }^{36}$, Rithie ${ }^{37}$, Moraes ${ }^{38}$, Blagg et al. ${ }^{39}$, Henriksen e Pohlenz ${ }^{40}$, Rugai et al. ${ }^{41}$, Moura e Oliveira $^{42}$, Granham ${ }^{43}$, Katz et al. ${ }^{44}$, Concentração por centrífugo sedimentação em éter-OS ${ }^{45}$. A coleta de três amostras de fezes em dias alternados foi realizada em seis ${ }^{4,16,21,24,28,30}$ dos 17 estudos que enfocaram as enteroparasitoses (dado não disponível em tabela).

As prevalências das doenças avaliadas foram expressas de diferentes maneiras, considerando- 
Tabela 2. continuação

\begin{tabular}{|c|c|c|c|}
\hline \multirow[b]{2}{*}{ Autor, ano } & \multicolumn{2}{|c|}{ Principais resultados } & \multirow[b]{2}{*}{ Escore } \\
\hline & Prevalências (\%) & Associações estatísticas & \\
\hline $\begin{array}{l}\text { Mascarini; } \\
\text { Donalísio, } \\
2006^{19}\end{array}$ & $\begin{array}{l}\text { - Corte } 1: 50,39 \\
\text { - Corte } 2: 34,0\end{array}$ & $\begin{array}{l}\text { Corte } 1 \\
\text { i) análises bivariada: } \\
\text { - sexo da criança } \\
\text { - idade da criança } \\
\text { - local de moradia } \\
\text { - tipo de casa } \\
\text { - renda familiar } \\
\text { - escolaridade da mãe } \\
\text { - tratamento da água } \\
\text { ii) análises multivariada: } \\
\text { - sexo da criança } \\
\text { - idade da criança } \\
\text { - renda familiar } \\
\text { - presença de animais domésticos } \\
\text { Corte } 2 \\
\text { i) análises bivariada: } \\
\text { - sexo da criança } \\
\text { - local de moradia } \\
\text { - tipo de casa } \\
\text { - renda familiar } \\
\text { - escolaridade da mãe } \\
\text { ii) análises multivariada: } \\
\text { - sexo criança } \\
\text { - renda familiar } \\
\text { - escolaridade da mãe } \\
\text { - presença de animais domésticos }\end{array}$ & 11 \\
\hline $\begin{array}{l}\text { Mascarini; } \\
\text { Donalísio, } \\
2006^{20}\end{array}$ & $\begin{array}{l}\text { Corte } 1 \\
\text { - G. duodenalis: } 23,7 \\
\text { - Helmintos: } 16,6 \\
\text { - Cryptosporidium sp: } 15,6 \\
\text { - B. hominis } 13,2 \\
\text { - E. coli: } 6,6 \\
\text { - E. nana: } 1,8 \\
\text { - Isospora sp: } 0,3 \\
\text { Corte } 2 \\
\text { - G. duodenalis: } 21,4 \\
\text { - Helmintos: } 9,1 \\
\text { - Cryptosporidium sp: } 3,8 \\
\text { - B. hominis } 5,5 \\
\text { - E. coli: } 4,5 \\
\text { - E. nana: } 2,0- \\
\text { Isospora sp: } 0,0\end{array}$ & $\begin{array}{l}\text { Corte } 1 \\
\text { i) G. duodenalis: } \\
\text { - idade da criança } \\
\text { - local de moradia } \\
\text { - renda familiar } \\
\text { - escolaridade da mãe } \\
\text { ii) Cryptosporidium sp: } \\
\text { - idade da criança } \\
\text { - local de moradia Corte } 2 \\
\text { i) G. duodenalis: } \\
\text { - idade da criança } \\
\text { - renda familiar } \\
\text { ii) Cryptosporidium sp: } \\
\text { - nenhuma associação }\end{array}$ & 8 \\
\hline
\end{tabular}

continua

se: i) a totalidade dos casos; ii) a faixa etária; iii) o tipo específico de doença/tipo de parasita; e iv) o atendimento em creche. A prevalência total de enteroparasitose variou entre $15,4 \%{ }^{27}$ a $63,0 \%{ }^{22}$. Considerando os estudos que avaliaram mais de dois parasitas, Giardia lamblia foi o mais prevalente em quatro estudos ${ }^{21,24,25,30}$, seguido de Giardia duodenalis que foi o mais prevalente em dois estudos $^{16,20}$.
Observa-se (dados não tabulados) que os pesquisadores buscaram discriminar um conjunto amplo de variáveis independentes da presença de infecções por parasitas, infecções respiratórias e doença diarreica, envolvendo:

- características biológicas das crianças: sexo (11 estudos), idade (12 estudos);

- condições nutricionais e de acesso a serviços de saúde das crianças: ingestão de legumes 
Tabela 2. continuação

\begin{tabular}{|c|c|c|c|}
\hline \multirow[b]{2}{*}{ Autor, ano } & \multicolumn{2}{|c|}{ Principais resultados } & \multirow[b]{2}{*}{ Escore } \\
\hline & Prevalências (\%) & Associações estatísticas & \\
\hline $\begin{array}{l}\text { Pupulin et al., } \\
2004^{21}\end{array}$ & $\begin{array}{l}\text { Creche } 1 \\
\text { - G. lamblia: } 26,2 \\
\text { - E. coli: } 0,0 \\
\text { - I. bustchlii: } 0,0 \\
\text { - E. vermicularis: } 0,0 \\
\text { - E. nana: } 0,0 \\
\text { Creche } 2 \\
\text { - G. lamblia: } 20,7 \\
\text { - E. coli: } 3,4 \\
\text { - I. bustchlii: } 3,4 \\
\text { - E. vermicularis: } 0,0 \\
\text { - E. nana: } 0,0 \\
\text { Creche } 3 \\
\text { - G. lamblia: } 24,1 \\
\text { - E. coli: } 24,1 \\
\text { - I. bustchlii: } 0,0 \\
\text { - E. vermicularis: } 13,8 \\
\text { - E. nana: } 6,9\end{array}$ & - & 10 \\
\hline $\begin{array}{l}\text { Gurgel et al., } \\
2005^{22}\end{array}$ & $\begin{array}{l}\text { Crianças assistidas em creches } \\
\text { - Enteroparasitoses: } 63,0 \\
\text { - Helmintos: } 43,0 \\
\text { - Protozoários: } 43,3 \\
\text { Crianças não assistidas em creches } \\
\text { - Enteroparasitoses: } 41,4 \\
\text { - Helmintos: } 31,4 \\
\text { - Protozoários: } 23,9\end{array}$ & $\begin{array}{l}\text { Houve diferença significativa nas } \\
\text { prevalências de enteroparasitoses, } \\
\text { helmintos e protozoários entre os } \\
\text { grupos estudados }\end{array}$ & 10 \\
\hline $\begin{array}{l}\text { Veríssimo, } \\
2005^{23}\end{array}$ & $\begin{array}{l}\text { Pneumonia (até } 3 \text { episódios) em } \\
\text { crianças }<3 \text { anos } \\
\text { - Total: } 27 \\
\text { - Creches universitárias: } 34,3 \\
\text { - Creches municipais: } 78,8 \\
\text { Gripe ou resfriado (até } 3 \text { episódios) em } \\
\text { crianças }<3 \text { anos } \\
\text { - Total: } 31,5 \\
\text { - Creches universitárias: } 80,7 \\
\text { - Creches municipais: } 24,9 \\
\text { Pneumonia (até } 3 \text { episódios) em } \\
\text { crianças } \geq 3 \text { anos } \\
\text { - Total: } 12,2 \\
\text { - Creches universitárias: } 14,7 \\
\text { - Creches municipais: } 41,3 \\
\text { Gripe ou resfriado (até } 3 \text { episódios) em } \\
\text { crianças } \geq 3 \text { anos } \\
\text { - Total: } 5,4 \\
\text { - Creches universitárias: } 40,1 \\
\text { - Creches municipais: } 25,6 \\
\text { Bronquite (até } 3 \text { episódios) em crianças } \\
\geq 3 \text { anos } \\
\text { - Total: } 5,4 \\
\text { - Creches universitárias: } 4,8 \\
\text { - Creches municipais: } 13,7\end{array}$ & $\begin{array}{l}\text { i) Pneumonia em crianças }<3 \text { anos } \\
\text { - tipo de creche (municipal) } \\
\text { ii) Gripe ou resfriado em crianças }<3 \\
\text { anos } \\
\text { - tipo de creche (universitária) } \\
\text { iii) Pneumonia em crianças } \geq 3 \text { anos } \\
\text { - tipo de creche (municipal) } \\
\text { iv) Gripe ou resfriado em crianças } \geq 3 \\
\text { anos } \\
\text { - tipo de creche (municipal) } \\
\text { v) Bronquite em crianças } \geq 3 \text { anos } \\
\text { - tipo de creche (municipal) }\end{array}$ & 10 \\
\hline
\end{tabular}

crus (1 estudo), estado nutricional (1 estudo), imunização (2 estudos);
- morbidade das crianças: histórico de doenças (2 estudos), diarreia associada à ocorrência 
Tabela 2. continuação

\begin{tabular}{|c|c|c|c|}
\hline \multirow[b]{2}{*}{ Autor, ano } & \multicolumn{2}{|c|}{ Principais resultados } & \multirow[b]{2}{*}{ Escore } \\
\hline & Prevalências (\%) & Associações estatísticas & \\
\hline $\begin{array}{l}\text { Uchoa et al., } \\
2001^{24}\end{array}$ & $\begin{array}{l}\text { Crianças } \leq 6 \text { anos } \\
\text { - G. lamblia: } 22,6 \\
\text { - A. lumbricoides: } 14 \\
\text { - T. trichiura: } 13,4 \\
\text { - E. coli: } 11,3 \\
\text { - E. nana: } 10,2 \\
\text { - E. histolytica: } 5,4 \\
\text { - B. hominis: } 1,1 \\
\text { - E. vermicularis: } 0,5 \\
\text { - H. nana: } 0,0 \\
\text { Crianças } 7 \text { - } 11 \text { anos } \\
\text { - G. lamblia: } 14,3 \\
\text { - A. lumbricoides: } 35,7 \\
\text { - T. trichiura: } 25,0 \\
\text { - E. coli: } 39,3 \\
\text { - E. nana: } 7,1 \\
\text { - E. histolytica: } 14,3 \\
\text { - B. hominis: } 3,6 \\
\text { - E. vermicularis: } 0,0 \\
\text { - H. nana: } 100\end{array}$ & - & 7 \\
\hline $\begin{array}{l}\text { Rocha et al., } \\
2000^{25}\end{array}$ & 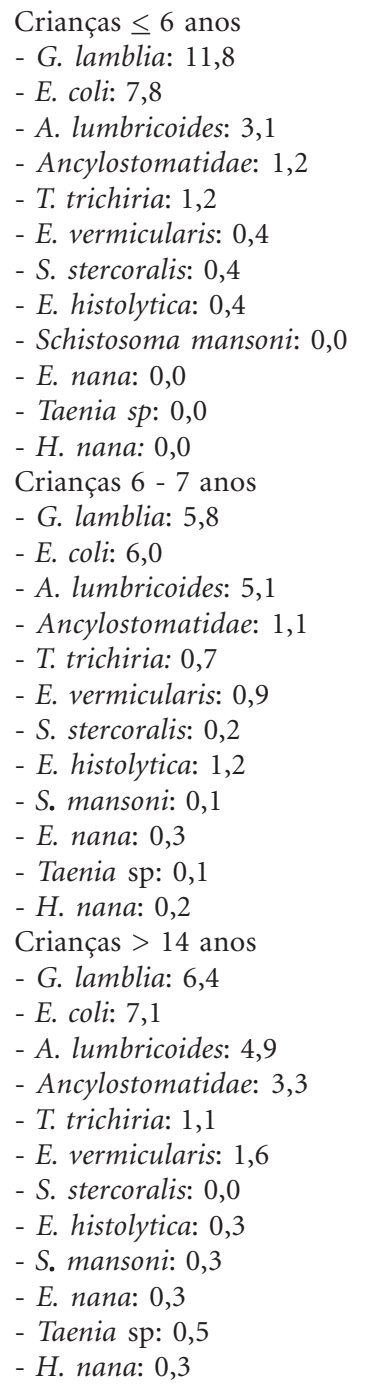 & $\begin{array}{l}\text { Houve diferença significativa nas } \\
\text { prevalências de G. lamblia entre os } \\
\text { grupos estudados }\end{array}$ & 8 \\
\hline
\end{tabular}


Tabela 2. continuação

\begin{tabular}{|c|c|c|c|}
\hline \multirow[b]{2}{*}{ Autor, ano } & \multicolumn{2}{|c|}{ Principais resultados } & \multirow[b]{2}{*}{ Escore } \\
\hline & Prevalências (\%) & Associações estatísticas & \\
\hline $\begin{array}{l}\text { Barros et al., } \\
1999^{26}\end{array}$ & $\begin{array}{l}\text { - Doença diarreica: Incidência de 2,3 } \\
\text { episódios por criança/ano } \\
\text { - Infecção respiratória inferior: } \\
\text { Incidência de } 0,34 \text { episódios por } \\
\text { criança/ano } \\
\text { - Infecção respiratória superior (valor de } \\
\text { incidência não reportado) }\end{array}$ & $\begin{array}{l}\text { i) Doença diarreica (análise } \\
\text { multivariável) } \\
\text { - uso de sabão no cuidado das } \\
\text { crianças } \\
\text { - presença de moscas } \\
\text { - lavagem das mãos antes das } \\
\text { refeições e após a defecação } \\
\text { ii) Infecção respiratória inferior } \\
\text { (análise multivariável) } \\
\text { - aglomeração } \\
\text { iii) Infecção respiratória superior } \\
\text { (análise multivariável) } \\
\text { - tamanho da sala de aula }\end{array}$ & 11 \\
\hline $\begin{array}{l}\text { Coelho et al., } \\
1999^{27}\end{array}$ & $\begin{array}{l}\text { - Enteroparasitoses: } 15,4 \\
\text { - A. lumbricoides: } 9,9 \\
\text { - T. trichiura: } 5,9 \\
\text { - E. vermicularis: } 1,2 \\
\text { - H. nana: } 0,2 \\
\text { - S. stercoralis: } 0,3\end{array}$ & - & 7 \\
\hline $\begin{array}{l}\text { Franco et al., } \\
1996^{28}\end{array}$ & $\begin{array}{l}\text { - G. duodenalis: } 13,3 \\
\text { - Cryptosporidium parvum: } 6,4\end{array}$ & $\begin{array}{l}\text { - i) G. lamblia } \\
\text { - idade da criança } \\
\text { ii) C. parvum } \\
\text { - idade da criança }\end{array}$ & 9 \\
\hline $\begin{array}{l}\text { Fuchs et al., } \\
1996^{29}\end{array}$ & $\begin{array}{l}\text { - Total: } 42,0 \\
\text { - Crianças não assistidas em creches: } \\
14,0 \\
\text { - Crianças assistidas em creches: } 53,0\end{array}$ & $\begin{array}{l}\text { i) análises bivariada } \\
\text { - escore de bens de consumo } \\
\text { - atendimento em creche } \\
\text { - número de horas na creche } \\
\text { ii) análise multivariável } \\
\text { - atendimento em creche } \\
\text { - número de horas na creche }\end{array}$ & 11 \\
\hline Guimarães e & G. Lamblia: 63,3 & - & 9 \\
\hline Sogayar, $1995^{30}$ & $\begin{array}{l}\text { A. lumbricoides: } 20,4 \\
\text { T. trichuira: } 19,0 \\
\text { E. vermiculares: } 4,8 \\
\text { Ancylostomatidae: } 3,4 \\
\text { S. stercolaris: } 4,8 \\
\text { H. nana: } 8,8 \\
\text { E. coli: } 22,4 \\
\text { B. hominis: } 32,0\end{array}$ & & \\
\hline $\begin{array}{l}\text { Birar et al., } \\
1994^{31}\end{array}$ & - Pneumonia: 41,4 & - & 7 \\
\hline $\begin{array}{l}\text { Torres et al., } \\
1992^{32}\end{array}$ & E. histolytica: 5,92 & - & 8 \\
\hline $\begin{array}{l}\text { Torres et al., } \\
1991^{33}\end{array}$ & G. lamblia: 32,80 & $\begin{array}{l}\text { - idade da criança } \\
\text { - mês do ano }\end{array}$ & 8 \\
\hline
\end{tabular}

NR: Não relatado. - : Não realizado.

de enteroparasitoses ( 2 estudos), sazonalidade (2 estudos);

- características socioeconômicas das famílias: renda (4 estudos), escores de bens de consumo (1 estudo), educação materna (5 estudos), tipo de casa (2 estudos), número de crianças dormindo no mesmo cômodo (1 estudo), número de irmãos (2 estudos);

- características higiênico-sanitárias: tratamento de água (2 estudos), presença de animais domésticos (2 estudos), higiene das crianças com o uso de sabão (1 estudo), lavagem das mãos 
antes das refeições ( 1 estudo), lavagem das mãos depois da defecação (1 estudo), presença de moscas durante as refeições (1 estudo);

- características das crianças associadas à institucionalização: frequência à creche ( 2 estudos), tempo de permanência na creche em um dia ( 1 estudo);

- características relacionadas à estrutura das creches: número de crianças na creche (1 estudo), número de crianças por turma (1 estudo), número de crianças por $\mathrm{m}^{2}$ ( 1 estudo), número de crianças por funcionário ( 1 estudo), tamanho da área ( 1 estudo), ventilação ( 1 estudo).

A associação estatística entre as variáveis independentes de estudo e os desfechos de interesse não foi realizada em alguns estudos. Análises multivariadas de associação estatística, com o controle adequado das possíveis variáveis de confundimento, foram conduzidas somente em três estudos, um analisando enteroparasitoses ${ }^{19}$, um analisando doença diarreica ${ }^{26}$ e dois analisando infecções respiratórias ${ }^{26,29}$.

Considerando os estudos sobre enteroparasitoses, cinco deles ${ }^{15,17,21,24,27}$ apresentaram somente resultados sobre a prevalência. Destaca-se que apenas um estudo ${ }^{14}$ avaliou a associação entre estado nutricional e enteroparasitoses.

As variáveis que mais vezes mostraram-se associadas ao desenvolvimento de enteroparasitoses, mantendo importância quando controlado o confundimento, foram a idade da criança $^{16,19,20,28,32,33}$, a renda familiar e a escolaridade materna ${ }^{16,19,20}$.

A maior prevalência de enteroparasitose em faixas etárias maiores foi encontrada no estudo de Mascarini e Donalisio ${ }^{19}$, ao avaliar a presença global de enteroparasitose, e no estudo de Carvalho et al. ${ }^{16}$ para Helmintos, Ascaris lumbricoides, Trichuris trichiura e Escherichia coli. Entretanto, apresentam-se resultados controversos na análise das categorias que apresentam maior risco, dificultado pela variedade encontrada na categorização da faixa etária. Os resultados para as variáveis renda familiar e escolaridade materna convergem ao destacar os estratos de renda inferiores e a menor escolaridade materna como importantes fatores de risco em relação à prevalência de enteroparasitoses ${ }^{16,19,20}$.

Para o caso das infecções respiratórias, estar frequentando creche, maior tempo de permanência na creche, menor tamanho da sala de aula e aglomeração, são importantes fatores de risco, segundo resultados de Barros et al. ${ }^{26}$ e de Fuchs et al. ${ }^{29}$. Ainda, observou-se uma maior ocorrência de infecções respiratórias nas crianças meno- res de três anos (nestes casos, as doenças avaliadas foram a pneumonia e a gripe ${ }^{23}$.

Ressalta-se que os estudos com comparação de grupos ${ }^{22,25,29}$ (crianças atendidas em creches versus crianças não atendidas em creches $^{22,29} \mathrm{e}$ crianças atendidas em creches versus crianças escolares $^{25}$ ) apontaram o atendimento em creche como fator de risco para no mínimo um dos desfechos em estudo. As prevalências de enteroparasitoses e de infecções respiratórias foram maiores no grupo de crianças assistidas em creches quando comparadas às crianças não assistidas ${ }^{22,29}$.

O escore metodológico foi, em média, de 8,86 pontos ( $\mathrm{DP}=1,46$ pontos), sendo 11 pontos $\mathrm{o}$ valor máximo atingido e sete o mínimo. Com o escore de 11 pontos destacaram-se três artigos, sendo os artigos que realizaram análises multivariadas ${ }^{19,26,29}$. As principais limitações dos estudos, segundo os critérios de Downs e Black ${ }^{11}$, foram a não descrição das razões das perdas de participantes e a não apresentação e controle dos principais fatores de confusão.

\section{Discussão}

Diante da importância das doenças infecciosas como causa de morbidade e mortalidade na infância, do uso crescente de creches pela população infantil e do paradigma sobre o maior risco de crianças que frequentam creches contraírem doenças infecto-parasitárias, o presente trabalho centrou atenção nos estudos sobre infecções respiratórias, doença diarreica e infecções por parasitas na população pré-escolar brasileira assistida em creches.

Apesar de sua importância, a doença diarreica foi analisada em um único estudo nesta revisão. Segundo Maranhão ${ }^{46}$, considerando a diarreia como o aumento do número de evacuações ao dia, associado ou não à diminuição da consistência das fezes, a elaboração de uma classificação da doença é dificultada devido à grande variabilidade na frequência das evacuações por idade e entre indivíduos e às percepções pessoais e culturais que podem influir sobre o que se considera consistência normal das fezes. Cogita-se, assim, que a definição controversa de diarreia e a impossibilidade do acompanhamento diário de crianças institucionalizadas pelas suas mães podem dificultar a obtenção de informações sobre episódios diarreicos nas creches.

As melhorias nas condições de saneamento ambiental têm contribuído para diminuição dos casos de diarreia nas crianças brasileiras. Esses 
avanços também levaram a uma mudança nos modos predominantes de transmissão, da transmissão fecal-oral por bactérias disseminadas como a Salmonella spp e Shigella spp, para a transmissão pessoa a pessoa por vírus disseminados (rotavírus, adenovírus, norovírus) ${ }^{47}$. Entretanto, as creches apresentam características que facilitam tanto o contato entérico quanto o contato pessoa-pessoa, particularmente a aglomeração e os hábitos higiênicos inadequados ${ }^{10}$.

Os estudos sobre infecções respiratórias mostraram-se bastante análogos quanto à magnitude do problema e seus determinantes. Nas crianças assistidas em creches, as altas frequências de infecções respiratórias estiveram associadas ao tempo que as crianças permanecem nesse ambiente e a características estruturais da creche/aglomeração. Esses fatores sintetizam a influência da creche como ambiente responsável por episódios de infecções respiratórias das vias aéreas. É comprovada a maior probabilidade de disseminação de doenças comunicáveis pessoa-pessoa em ambientes de maior aglomeração ${ }^{48}$. Em linhas gerais, considera-se que o agrupamento de crianças numa situação de diária e prolongada coexistência (10-12 horas), recebendo atendimento de forma coletiva, em locais fechados e sem condições de higiene adequada pode facilitar a disseminação de doenças, conferindo à creche epidemiologia característica na transmissão de infecções ${ }^{10,19}$. Cabe ressaltar que alguns agentes de infecções respiratórias também podem ser transmitidos através da via fecal-oral, mostrando a importância da higiene pessoal na prevenção dessas doenças ${ }^{49}$.

A ampla variabilidade nas prevalências de enteroparasitoses observadas no Brasil, como as mostradas nesta revisão, foi explicada por Fonseca et al. ${ }^{50}$ pelas condições socioeconômicas e o grau de desenvolvimento dos sistemas de saúde de cada região. Tanto indicadores de morbidade de base não hospitalar quanto de base hospitalar revelam as desigualdades inter-regionais no contexto das doenças infecciosas e parasitárias, com cifras mais elevadas nas regiões Norte e Nordes$t e^{51}$. Na presente revisão, a concentração de estudos no Sudeste do país inviabiliza a análise de tais diferenças. Entretanto, os resultados encontrados na cidade de Aracajú ${ }^{22}$ são indicativos da situação na região Nordeste do país, valorizando a importância de maior quantidade de estudos pautados nas desigualdades socioespaciais do país. A concentração da produção científica em temas de saúde na região Sudeste do Brasil tem sido apontada por outros pesquisadores ${ }^{52,53}$.
Apesar da variabilidade encontrada nas prevalências de enteroparasitoses, considerando a menor prevalência total de $15,4 \%$ e a proporção maior de $10 \%$ para no mínimo um parasito, nos estudos que avaliaram parasitos específicos, as cifras podem ser consideradas significativas. Dados nacionais também são indicativos da relevância que ainda apresentam as doenças infecciosas e parasitárias como problema de saúde pública no Brasil. À exceção das doenças imunopreveníveis, as demais doenças infecciosas e parasitárias vêm se mantendo no Brasil num patamar quase constante nos últimos anos, representando cerca de $10 \%$ das causas de internações hospitalares na rede hospitalar pública e contratada pelo SUS anualmente, sendo esses valores mais elevados nas regiões Norte e Nordeste ${ }^{51,54}$. Em estudo recente, realizado na cidade de $\mathrm{Ma}$ naus, por exemplo, as doenças cardiovasculares, as infecções respiratórias das vias aéreas inferiores e as doenças diarreicas foram responsáveis por cerca de $3 / 4$ das internações ${ }^{55}$.

A sobreposição de etapas (doenças infectoparasitárias e crônico-degenerativas com grande importância absoluta e relativa) vem sendo destacada como uma das características distintivas do processo de transição epidemiológica no Brasil. Nesse processo, observa-se uma tendência de redução proporcional do peso das doenças infecciosas e parasitárias enquanto causas de morte, porém não verificado quando se analisam os dados de morbidade. A emergência e reemergência de doenças infecciosas e parasitárias no Brasil explica-se por suas peculiaridades geográficas, climáticas e ecológicas, assim como pelas características de sua formação social, política, econômica e cultural ${ }^{54}$.

Entre as enteroparasitoses, a infecção por $G$. lamblia foi a mais prevalente em maior quantidade de estudos. A contaminação por G.lamblia é mais comum por ingestão de cistos presentes na água, que podem também ser carreados por moscas caseiras. A transmissão de pessoa a pessoa também é observada, principalmente em ambientes com pouca higiene ${ }^{56}$. A giardíase é mais prevalente em crianças, especialmente aquelas institucionalizadas em creches, nas quais a falta de hábitos de higiene e as precárias condições sanitárias facilitam o contato íntimo com as formas infectantes ${ }^{57}$. Tais fatores, aliados à baixa imunidade contra o parasita, podem resultar em altos níveis de infecção nessa população ${ }^{15}$. A G. lamblia é uma das principais causas de diarreia em crianças, podendo também contribuir para ocorrência de carências nutricionais ${ }^{56}$. Outros 
parasitas, como a Endolimax nana e a E. coli, possuem o mesmo mecanismo de transmissão da G. lamblia. Estas parasitoses apresentam importante implicação na epidemiologia das doenças parasitárias, haja vista que a sua presença pode servir como indicador das condições sociossanitárias e da contaminação fecal a que os indivíduos estão expostos ${ }^{58}$.

A maior prevalência de enteroparasitoses nas crianças de maior idade pode estar relacionada ao processo de crescimento e de desenvolvimento infantil, que permite a criança uma maior mobilidade e interação com o meio ambiente ${ }^{19}$. Nesse contexto, destaca-se o maior contato da criança com o solo, fator este que predispõe a aquisição de enteroparasitoses ${ }^{57}$.

A disparidade socioeconômica nas prevalências de enteroparasitoses foi marcada pela significativa associação com a renda familiar e a escolaridade materna. Os baixos níveis de renda dificultam o acesso da população a bens e serviços essenciais à manutenção da saúde, tais como alimentação, moradia e saneamento básico, criando um ambiente favorável para o surgimento de carências nutricionais e à aquisição de infecções e/ ou infestações ${ }^{59}$. Por sua vez, o nível educacional constitui um aspecto importante no combate de doenças infecto-contagiosas, na medida em que possibilita uma melhor compreensão destas, das formas de transmissão e de sua prevenção ${ }^{58,60}$.

Não existe um método capaz de diagnosticar, ao mesmo tempo, todas as formas parasitárias. Alguns métodos são mais gerais, permitindo o diagnóstico de vários parasitas intestinais, outros são métodos específicos, indicados para um parasita em especial. Devido a este fato estudos sobre prevalência de enteroparasitose priorizam os métodos gerais, possibilitando a comparabilidade de diversos estudos sobre o tema ${ }^{61}$. O método de sedimentação, o de maior utilização pelos autores da presente revisão, apesar de não possibilitar diagnosticar alguns parasitas, é um dos métodos gerais para o diagnóstico de enteroparasitose e o utilizado na rede pública de saú$\mathrm{de}^{62}$. Outros métodos, dos que possibilitam analisar vários parasitas, como o de centrifugação, também foi de grande utilização. Sendo assim, admite-se a comparabilidade dos resultados sobre os estudos de enteroparasitoses.

Ainda que o controle do confundimento não tenha sido uma prática comum nos estudos analisados, a influência da instrução materna e da renda no desenvolvimento de enteroparasitoses, mostrada nas análises bivariadas em estudos bem detalhados, evidencia sua consistência atra- vés do adequado controle de variáveis de confundimento. As maiores prevalências de enteroparasitoses encontradas em crianças assistidas em creches quando comparadas a crianças não assistidas, ao mesmo tempo em que indica o risco que representa o ambiente colocado pelas creches, supõe indiretamente a influência da situação socioeconômica. Fazer constar nos artigos publicados a possibilidade de ocorrência de variáveis de confusão é uma característica metodológica fundamental para o reconhecimento da pertinência dos estudos realizados ${ }^{63}$, sendo este um item relevante na avaliação da validade interna dos estudos ${ }^{64}$. Logo, há a necessidade de mais estudos com desenhos capazes de diminuir essas limitações e detectar tais associações.

Apesar de limitações metodológicas em alguns estudos, a atenção a critérios metodológicos rendeu elevada pontuação a outros estudos considerando os critérios de Downs e Black ${ }^{11}$. Por outro lado, a representatividade dos estudos garante a generalização dos resultados. Assim, os dados desta revisão permitem concluir que as infecções respiratórias e parasitárias constituem problemáticas importantes nas crianças institucionalizadas em creches, sendo a frequência à creche um fator importante no desenvolvimento dessas doenças. Tal fato pode estar relacionado a características biológicas inerentes à criança (idade), assim como a aspectos relacionados à creche (aglomeração e condições higiênicas) e as condições socioeconômicas das famílias (renda familiar e a escolaridade materna) nas quais estas crianças estão inseridas. Nesse contexto, a solução para estes problemas perpassa uma complexa rede de fatores, que incluem melhorias nas condições socioeconômicas, no saneamento básico e na infraestrutura das creches. Ainda, é de se considerar a importância dos programas de educação em saúde, que forneçam aos funcionários das creches e à comunidade os conhecimentos necessários para uma melhor assistência à criança. Tais ações podem contribuir para melhoria da saúde da população infantil, reduzindo os custos do Estado e das famílias com assistência médica, assim como o sofrimento humano relacionado à doença e, eventualmente, a morte.

\section{Considerações finais}

Evidências mostram uma associação positiva entre a permanência de crianças em creches e seu estado nutricional ${ }^{1}$. Entretanto, o aumento de episódios de doenças infecto-contagiosas, asso- 
ciado à institucionalização, pode repercutir negativamente no estado nutricional das crianças ${ }^{65}$. Verifica-se, portanto, posições contraditórias a respeito da influência da frequência à creche sobre o estado nutricional das crianças. Apesar disso, apenas um estudo incluído nesta revisão avaliou a associação entre o estado nutricional e a ocorrência de enteroparasitose.

Segundo Ramos ${ }^{56}$, os parasitas intestinais podem afetar o equilíbrio nutricional do indivíduo. A espoliação nutricional pode estar relacionada ao fato de o parasita alimentar-se de sangue, líquidos intersticiais e reservas orgânicas do hospedeiro. Em contrapartida, as carências nutricionais na infância podem induzir a déficits de maturação biológica, em especial do sistema imune $^{66}$, o qual exerce um papel importante na defesa do organismo contra agentes parasitá$\operatorname{rios}^{56}$. Assim, torna-se evidente a dificuldade ine- rente à interpretação dos resultados de estudos que envolvam a associação entre parasitoses e estado nutricional, haja vista que estes fatores podem coexistir na população e se influenciarem mutuamente, sendo difícil determinar o que é causa e o que é efeito ${ }^{56,67}$.

O desenvolvimento de estudos que concentrem análises sobre os efeitos prejudiciais dos distúrbios nutricionais e das enteroparasitoses sobre o crescimento infantil são importantes para aperfeiçoar a discussão da bidirecionalidade entre a carga de morbidade e a desnutrição na infância. Estes estudos devem compreender o monitoramento do crescimento, tornando possível apurar/comprovar as duas tendências que devem ser esperadas, a de melhorar o estado nutricional e a de contrair mais doenças infecciosas. Esses resultados poderiam alertar para os benefícios advindos da adoção de medidas preventivas conjuntas.

\section{Colaboradores}

D Figueroa Pedraza e D Queiroz participaram da elaboração do projeto, concepção do manuscrito, revisão bibliográfica, análise e interpretação dos dados, redação, revisão crítica e aprovação final do artigo. MC Sales participou da redação, revisão crítica e aprovação final do artigo. 


\section{Referências}

1. Pereira AS, Lanzillotti HS, Soares EA. Frequência à creche e estado nutricional de pré-escolares: uma revisão sistemática. Rev Paul Pediatr 2010; 28(4):366372.

2. Cuervo MRM, Aerts DRGC, Halpern R. Vigilância do estado nutricional das crianças de um distrito de saúde no Sul do Brasil. J Pediatr 2005; 81(4):325-331.

3. Fisberg RM, Marchion DML, Cardoso MRA. Estado nutricional e fatores associados ao déficit de crescimento de crianças frequentadoras de creches públicas do Município de São Paulo, Brasil. Cad Saude Publica 2004; 20(3):812-817.

4. Barçante TA, Cavalcanti DV, Silva GAV, Lopes PB, Barros RF, Ribeiro GP, Neubert LF, Barçante JMP. Enteroparasitos em crianças matriculadas em creches públicas do município de Vespasiano, Minas Gerais. Rev Pat Trop 2008; (1):33-42.

5. Cardoso SG, Santana ADC, Aguiar CP. Frequência e aspectos epidemiológicos da giardíase em creches no município de Aracaju, SE, Brasil. Rev Soc Bras Med Trop 1995; 28(1):25-31.

6. Franco RMB. Infecções parasitárias em creches: estudo em uma área urbana, com ênfase em Cryptosporidium parvum e Giardia duodenalis. Rev Soc Bras Med Trop 1997; 30(5):423-424.

7. Nesti MMM, Goldbaum M. Infectious diseases and daycare and preschool education. J Pediatr 2007; 83(4):299-312.

8. Segall-Corrêa AM, Gonçalves NNS, Chalita LVAS, Russo-Leite GP, Padovani CR, Gonçalves A. Determinantes da evolução do peso e altura em crianças de 3 meses a 6 anos assistidas em creche: análise por modelo linear não hierarquizado em ensaio quase-experimental. Rev Panam Salud Publica 2002; $12(1): 19-25$.

9. Macedo SEC, Menezes AMB, Albernaz E, Post P, Knorst M. Fatores de risco para internação por doença respiratória aguda em crianças até um ano de idade. Rev Saude Publica 2007; 41(3):351-358.

10. Benicio MHD, Cardoso MRA, Gouveia NC, Monteiro CA. Tendência secular da doença respiratória na infância na cidade de São Paulo (1984-1996). Rev Saude Publica 2000; 34(Supl. 6):91-101.

11. Downs HS, Black N. The feasibility of creating a checklist for the assessment of the methodological quality both of randomised and non-randomised studies of health care interventions. J Epidemiol Community Health 1998; 52(6):377-384.

12. Sanderson S, Tatt ID, Higgins JPT. Tools for assessing quality and susceptibility to bias in observational studies in epidemiology: a systematic review and annotated bibliography. Int J Epidemiol 2007; 36(3):666-676.

13. Vandenbroucke JP, Von Elm E, Altman DG, Gøtzsche PC, Mulrow CD, Pocock SJ, Poole C, Schlesselman JJ, Egger M; STROBE Initiative. Strengthening the reporting of observational studies in epidemiology (STROBE): explanation and elaboration. Epidemiology 2007; 18(6):805-835.

14. Biscegli TS, Romera J, Candido AB, Santos JM, Candido ECA, Binotto AL. Estado nutricional e prevalência de enteroparasitoses em crianças matriculadas em creche. Rev Paul Pediatr 2009; 27(3):289-295.
15. Menezes AL, Lima VMP, Freitas MTS, Rocha MO, Silva EF, Dolabella SS. Prevalence of intestinal parasites in children from public daycare centers in the city of Belo Horizonte, Minas Gerais, Brazil. Rev Inst Med Trop 2008; 50(1):57-59.

16. Carvalho TB, Carvalho LR, Mascarini LM. Occurrence of enteroparasites in day care centers in Botucatu (São Paulo State, Brazil) with emphasis on Cryptosporidium sp., Giardia duodenalis and Enterobius vermicularis. Rev Inst Med Trop 2006; 48(5):269273.

17. Chaves EMS, Vazquez L, Lopes K, Flores J, Oliveira L, Rizzi L, Fares EY, Querol M. Levantamento de Protozoonoses e Verminoses nas sete creches municipais de Uruguaiana, Rio Grande do Sul - Brasil. RBAC 2006; 38(1):39-41.

18. Gonçalves EMN, Silva AJ, Eduardo MBP, Uemura IH, Moura INS, Castilho VLP, Corbett CE. Multilocus genotyping of Cryptosporidium hominis associated with diarrhea outbreak in a day care unit in São Paulo. Clinics 2006; 61(2):119-126.

19. Mascarini LM, Donalisio MR. Epidemiological aspects of enteroparasitosis at daycare centers in the city of Botucatu, State of São Paulo, Brazil. Rev Bras Epidemiol 2006; 9(3):297-308.

20. Mascarini LM, Donalisio MR. Giardíase e criptosporidiose em crianças institucionalizadas em creches no Estado de São Paulo. Rev Soc Bras Med Trop 2006; 39(6):577-579.

21. Pupulin ART, Gomes ML, Dias MLGG, Araújo SM, Guilherme ALF, Kuhl. Giardíase em creches do município de Maringá, PR. RBAC 2004; 36(3):147149.

22. Gurgel RQ, Queiroz R, Cardoso GS, Silva AM, Santos LN, Oliveira RCV. Creche: ambiente expositor ou protetor nas infestações por parasitas intestinais em Aracaju, SE. Rev Soc Bras Med Trop 2005; 38(3):267-269.

23. Veríssimo MDLOR. Ocorrência de agravos respiratórios em creches universitárias e municipais na cidade de São Paulo. Rev Bras Cresc Desenv Hum 2005; 15(2):1-12.

24. Uchôa CMA, Lobo AGB, Bastos OMP, Matos AD. Parasitoses intestinais: prevalência em creches comunitárias da cidade de Niterói, Rio de Janeiro Brasil. Rev Inst Adolfo Lutz 2001; 60(2):97-101.

25. Rocha RS, Silva JG, Peixoto SV, Caldeira RL, Firmo JOA, Araújo JO, Carvalho OS, Katz N. Avaliação da esquistossomose e de outras parasitoses intestinais, em escolares do município de Bambuí, Minas Gerais, Brasil. Rev Soc Bras Med Trop 2000; 33(5):431436.

26. Barros AJD, Ross DA, Fonseca WVC, Williams LA, Moreira-Filho DC. Preventing acute respiratory infections and diarrhoea in child care centres. Acta Paediatr 1999; 88(10):1113-1118.

27. Coelho LMPS, Aidar Sobrinho T, Oliveira SM, Ikegami M, Yoshizumi AM, Nakamoto AYK, Brotto SA, Felberg S, Maiorano MR. Ovos e larvas de helmintos nos sanitários de pré-escolas municipais de Sorocaba, SP e suas freqüências nas fezes das crianças. Rev Soc Bras Med Trop 1999; 32(6):647-652. 
28. Franco RMBF, Cordeiro NS. Giardíase e criptosporidiose em creches no município de Campinas, SP. Rev Soc Bras Med Trop 1996; 29(6):585-591.

29. Fuchs SC, Maynart RC, Costa LF, Cardozo A, Schierholt R. Duration of day-care attendance and acute respiratory infection. Cad Saude Publica 1996; 12(3):291-296.

30. Guimarães S, Sogayar MIL. Occurrence of Giardia lamblia in children of municipal day-care centers from Botucatu, São Paulo state, Brazil. Rev Inst Med Trop 1995; 37(6):501-506.

31. Bitar ML, Latorre MRDO, Viude A, Takahashi LN, Silva VPP. Caracterização da saúde de crianças atendidas em creches e prevenção dos distúrbios de comunicação. Rev Saude Publica 1994; 28(1):46-58.

32. Torres DMAGV, Chieffi PP, Costa WA, Vellosa SAG, Dias RMDS, Mangini AC. Infecção por Entamoeba histolytica em creches mantidas pela prefeitura do município de São Paulo, SP, Brasil, 1982-1983. Rev Bras Anal Clin 1992; 24(1):8-10.

33. Torres DMAGV, Chieffi PP, Costa WA, Kudzielics E. Giardíase em creches mantidas pela prefeitura do município de São Paulo, 1982/1983. Rev Inst Med Trop 1991; 33(2):137-142.

34. Neves DP, Melo AL, Genaro O, Linardi PM. Parasitologia Humana. 11ª Edição. Belo Horizonte: Atheneu; 2010.

35. Faust EC, Sawitz W, Tobie J, Odon V, Peres C, Lincicome DR. Comparative efficiency of various technics for the diagnosis of protozoa and helmints in feces. J Parasitol 1939; 25(3):241-262.

36. Amato Neto V, Corrêa LL. Exame parasitológico de fezes. 4a Edição. São Paulo: Sarvier; 1980.

37. Ritchie LS. An ether sedimentation technique for routhine stool examinations. Bull U S Army Med Dep 1948; 8(4):326.

38. Moraes RG. Contribuição para o estudo do Strongyloides stercoralis e da estrongiloidose no Brasil. Rev Serv Saúde Públ (Rio de J.) 1948; 1:507-624.

39. Blagg W, Schoegel EL, Mansour NS, Khalaf GI. A new concentration technic for demonstration of protozoa and helminth eggs in feces. Amer J Trop Med Hyg 1955; 4(1):23-28.

40. Henriksen AS, Pohlenz JFL. Stanining of Cryptosporidium by a modified Ziehl-Neelsen technique. Acta Vet Scand 1981; 22:594-596.

41. Rugai E, Mattos T, Brisola AP. Nova técnica para isolar larvas de nematóides das fezes: modificações do método de Baermann. Rev Instit Adolfo Lutz $1954 ; 14: 5-8$.

42. Moura H, Oliveira LM. Cryptosporidium: parasitose de imunocomprometidos. Rev Bras Patol Clín 1985; 21(6):198-202.

43. Graham CFA. Device for the diagnosis of enterobius infection. Am J Trop Med 1941; 21(1):159-161.

44. Katz N, Chaves A, Pellegrino P. A simple device for quantitative stool thick-smear technique in Schistosomiasis mansoni. Rev Inst Med Trop S Paulo 1972; 14(6):397-402.

45. Waldman E, Tzipori S, Forsyth JRL. Separation of Cryptosporidiosis species oocysts from feces by using a Percoll discontinuous density gradient. JCM 1986; 23(1):199-200.
46. Maranhão HS. Diarreia aguda: aspectos clínicosepidemioloógicos, evolução nutricional e isolamento de entropatógenos em lactantes na cidade do Natal, Nordeste do Brasil. The Elect J Ped Gas Nut Liv Dis 2001; 5(5):1-225.

47. Barreto ML, Teixeira MG, Bastos FI, Ximenes RAA, Barata RB, Rodrigues LC. Sucessos e fracassos no controle de doenças infecciosas no Brasil: o contexto social e ambiental, políticas, intervenções e necessidades de pesquisa. Lancet 2011; (Saúde no Brasil 3):47-60

48. Amorim KS, Rossetti-Ferreira MC. Análise crítica de investigações sobre doenças infecciosas respiratórias em crianças que freqüentam creche. J Pediatr 1999; 75(5):313-320.

49. Cairncross S. Handwashing with soap - a new strategy to prevent ARIs? Trop Med Int Health 2003; 8:677-679.

50. Fonseca EOL, Teixeira MG, Barreto ML, Carmo EH, Costa MCN. Prevalência e fatores associados às geo-helmintíases em crianças residentes em municípios com baixo IDH no Norte e Nordeste brasileiros. Cad Saude Publica 2010; 26:143-152.

51. Brasil. Ministério da Saúde (MS). Secretaria de Vigilância em Saúde. Departamento de Vigilância Epidemiológica. Doenças infecciosas e parasitárias: guia de bolso/Ministério da Saúde, Secretaria de Vigilância em Saúde. 6ª Edição. Brasília: MS; 2005. (Série B. Textos Básicos de Saúde).

52. Drumond EF, Machado CJ, Vasconcelos MR, França E. Utilização de dados secundários do SIM, Sinasc e SIH na produção científica brasileira de 1990 a 2006. $R$ bras Est Pop 2009; 26(1):7-19.

53. Canella DS, Silva ACF, Jaime PC. Produção científica sobre nutrição no âmbito da Atenção Primária à Saúde no Brasil: uma revisão de literatura. Cien Saude Colet 2013; 18(2):297-208.

54. Luna EJA. A emergência das doenças emergentes e as doenças infecciosas emergentes e reemergentes no Brasil. Rev Bras Epidemiol 2002; 5(3):229-243.

55. Medeiros MS, Sacramento DS, Hurtado-Guerrero JC, Ortiz RA, Fenner ALD. Custo das doenças atribuíveis a fatores ambientais na cidade de Manaus Amazonas. Cien Saude Colet 2013; 19(2):599-608.

56. Ramos GCSC. Correlação entre parasitoses intestinais, estado nutricional, condições socioeconômicas e sanitárias de crianças de três creches públicas do $\mathrm{mu}$ nicípio de Niterói [dissertação]. Niterói (RJ) Universidade Federal Fluminense; 2006.

57. Gonçalves ALR, Belizário TL, Pimentel JB, Penatti MPA, Pedroso RS. Prevalence of intestinal parasites in preschool children in the region of Uberlândia, State of Minas Gerais, Brazil. Rev Soc Bras Med Trop 2011; 44(2):191-193.

58. Pezzi NC, Tavares RG. Relação de aspectos sócioeconômicos e ambientais com parasitoses intestinais e eosinofilia em crianças da Enca, Caxias do Sul-RS. Estudos 2007; 34(11/12):1041-1055.

59. Sales MC, Queiroz EO, Paiva AA. Association between anemia and subclinical infection in children in Paraíba State, Brazil. Rev Bras Hematol Hemoter 2011; 33(2):96-99. 
60. Visser S, Giatti LL, Carvalho RAC, Guerreiro JCH. Estudo da associação entre fatores socioambientais e prevalência de parasitose intestinal em área periférica da cidade de Manaus (AM, Brasil). Cien Saude Colet 2011; 16(8):3481-3492.

61. De Carli GA. Parasitologia clínica: seleção de métodos e técnicas de laboratório para o diagnóstico das parasitoses humanas. Rio de Janeiro: Atheneu; 2001.

62. Visser S, Giatti LL, Chaves de Carvalho RA, Guerreiro JCH. Estudo da associação entre fatores socioambientais e prevalência de parasitose intestinal em área periférica da cidade de Manaus (AM, Brasil). Cien Saude Colet 2011; 16(8):3481-3492.

63. Moreno AB, Lopes CS. Avaliação da qualidade de vida em pacientes laringectomizados: uma revisão sistemática. Cad Saude Publica 2002; 18(1):81-92.

64. Araujo DMR, Vilarim MM, Sabroza AR, Nardi AE. Depressão no período gestacional e baixo peso ao nascer: uma revisão sistemática da literatura. $\mathrm{Cad}$ Saude Publica 2010; 26(2):219-227.

65. Sousa CPC, Sousa MPC, Rocha ACD, Figueroa Pedraza D. Perfil epidemiológico do estado nutricional de crianças assistidas em creches no Estado da Paraíba. Nutrire 2001; 36(1):111-126.

66. Macêdo EMC, Amorim MAF, Silva ACS, Castro CMMB. Efeitos da deficiência de cobre, zinco e magnésio sobre o sistema imune de crianças com desnutrição grave. Rev Paul Pediatr 2010; 28(3):329336.

67. Muniz-Junqueira MI, Queiróz EFO. Relationship between protein-energy malnutrition, vitamin A, and parasitoses in children living in Brasília. Rev Soc Bras Med Trop 2002; 35(2):133-141.

Artigo apresentado em 08/04/2012

Aprovado em 15/06/2012

Versão final apresentada em 20/06/2012 